\title{
Robot-assisted sacral tumor resection: a preliminary study
}

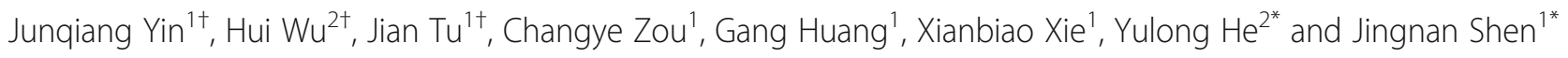

\begin{abstract}
Background: Few studies have been done on robot-assisted sacral surgery. This study aims to evaluate the outcomes of seven patients with benign sacral or presacral tumors treated with a robotic surgical system at a single center.
\end{abstract}

Methods: All patients with benign sacral or presacral tumors who underwent transperitoneal resection (between June 2015 and June 2016) using the da Vinci Si HD robotic surgical system (Intuitive Surgical Inc.) were included in this retrospective study.

Results: Seven patients with a mean age of 43.8 years (range: 22- 62 years) were included in this study. The operation time ranged from 60 to 335 min. Five out of these seven patients with presacral tumor underwent complete tumor resection by the da Vinci robotic surgical system, with a median blood loss of $52 \mathrm{ml}$. The other patients underwent excision of the presacral tumor by the da Vinci robotic surgical system, followed by a posterior approach, with a median blood loss of $675 \mathrm{ml}$. The histological diagnosis was schwannoma of the sacral nerve in five cases (71.5\%). The other two cases were chordoma and solitary fibroma of the sacrum, respectively. No perioperative or postoperative complications were encountered. The average hospitalization stay was 5.7 days. No recurrences were found at follow-up 24 to 31 months later.

Conclusion: Robot-assisted minimally invasive sacral surgery can provide precise dissection of the tissue under a perfect view. It is a technically feasible procedure that is associated with minimal blood loss, fewer injuries and short hospitalization. It is particularly suitable for presacral benign tumors.

Keywords: Robot-assisted surgery, Da Vinci surgical system, Sacral tumor

\section{Background}

Primary tumors originated from sacrum or retraperitioneal area are rare. Most of them are benign or low-grade malignancies, such as chondrosarcoma and schwannoma $[1,2]$. The resection of the tumor was one of the most important treatments for primary malignant sacral tumors, which could be performed using anterior, posterior, lateral and combined surgical approaches. The treatment of primary sacral tumors can be challenging because of the complex surrounding anatomical structures and the

\footnotetext{
*Correspondence: yulonghe@163.com; shenjingnan@126.com

†Junqiang Yin, Hui Wu and Jian Tu contributed equally to this work.

${ }^{2}$ Department of gastrointestinal surgery, First Affiliated Hospital of Sun

Yat-Sen University, Guangzhou 510080, China

'Department of Musculoskeletal Oncology, First Affiliated Hospital of Sun

Yat-Sen University, Guangzhou 510080, China
}

large size of the tumor [3]. The da Vinci surgical system is widely used in gastrointestinal surgery, urology and gynecological surgery, as it can provide the following advantages [4-6]. It can provide 3D vision and visual magnification (up to 15- times), which can promote more precise resection. Additionally, the da Vinci surgical system consists of three or four robotic arms, mimicking human wrist movements, with a high degree of freedom. However, there is no report about the performance of the da Vinci surgical system in the resection of sacral tumor.

We aimed to investigate the feasibility and efficiency of the da Vinci surgical system in the resection of sacral tumors.

(c) The Author(s). 2018 Open Access This article is distributed under the terms of the Creative Commons Attribution 4.0 International License (http://creativecommons.org/licenses/by/4.0/), which permits unrestricted use, distribution, and reproduction in any medium, provided you give appropriate credit to the original author(s) and the source, provide a link to the Creative Commons license, and indicate if changes were made. The Creative Commons Public Domain Dedication waiver (http://creativecommons.org/publicdomain/zero/1.0/) applies to the data made available in this article, unless otherwise stated. 


\section{Methods}

\section{Patients}

Patients with a sacral or presacral tumor who were treated using da Vinci surgical system at the First Affiliated Hospital of Sun Yat-sen University between June 2015 and January 2016 were enrolled in this retrospective study. Written informed consent to participate in the study was obtained from participants. This study was approved by the Institutional Ethical Board of the First Affiliated Hospital of Sun Yat-sen University.

The criteria for case inclusion were as follows: (1) presence of a tumor located in sacral or pre-sacral area; (2) operated by da Vinci surgical system. Patients with previous sacral or presacral surgery history were excluded following a discussion. Patients without completed follow-up information were excluded.

\section{Surgical treatment procedure}

Clinical assessment, including a thorough history, physical examination, digital rectal examination, routine blood tests, chest X-ray, computerized tomography, magnetic resonance imaging of the pelvis and needle biopsy, was completed for all patients before robotic surgery.

With patients in the supine position, general anesthesia was administered for patients (Fig. 1). A small incision was made on the right side $3 \mathrm{~cm}$ above the umbilicus to place a 12-mm trocar for the camera. The other three $8-\mathrm{cm}$ trocars were placed as shown in the Fig. 1. The pressure of the pneumoperitoneum was maintained at $15 \mathrm{mmHg}$. The posterior peritoneum was dissected to expose the tumor in the presacral area, according to the location of the tumor. The anterior approach allowed the surgeon to identify and protect the internal iliac vessels, ureter and rectum and determine the proper plane of the resection. The tumor was resected and removed only using the anterior approach if the tumor size was not too large or the location was proper. However, the posterior

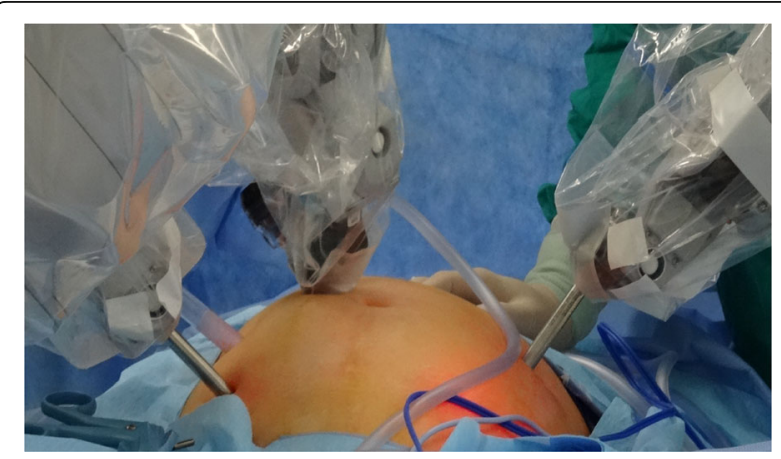

Fig. 1 surgical position and trocars placement approach was then used for tumor removal and spinopelvic reconstruction if necessary.

\section{Outcome assessment}

Data on peri-operative outcomes, operation time, blood loss, time to eating liquid, hospitalization, cost and complications were recorded. Data on postoperative outcomes, the function assessment (motor and sensory function assessment), tumor recurrence and metastasis (X ray and MRI) were examined every 3 months for Years 1 and 2, every 6 months for Years 3 to 5 and yearly thereafter, as our previous studies described [7].

\section{Result}

Seven patients were included in this study and successfully underwent operation suing the da Vinci surgical system (Table 1). Five of the patients with presacral tumor were operated using only anterior approach, as the tumor sizes were $37.7 \mathrm{~cm}^{3}, 113.0 \mathrm{~cm}^{3}, 39.3 \mathrm{~cm}^{3}, 141.4 \mathrm{~cm}^{3}$ and $96.3 \mathrm{~cm}^{3}$, and the locations were proper (Fig. 2). The operation time of these 5 patients were $60 \mathrm{~min}$, $90 \mathrm{~min}, 100 \mathrm{~min}, 80 \mathrm{~min}$ and $90 \mathrm{~min}$, respectively, and the blood loss amounts were $50 \mathrm{ml}, 100 \mathrm{ml}$, $30 \mathrm{ml}, 50 \mathrm{ml}$ and $30 \mathrm{ml}$ respectively. The fourth patient with schwannoma was operated on using the anterior and posterior approaches, as the size was $433.4 \mathrm{~cm}^{3}$. Additionally, it was adjacent to the greater sciatic foramen and sciatic nerve (Fig. 3). The posterior approach was taken to ensure the safe separation of the tumor from sciatic nerve and vessels accompanied. The operation time of this patient was $200 \mathrm{~min}$, and the blood loss amount was $600 \mathrm{ml}$. The fifth patient, with chordoma and sacrum involved, was operated on using anterior and posterior approaches. The ovarian artery was closely related to the tumor, so the da Vinci surgical system was employed to separate this vessel and ligature the presacral vessels. The operation time of this patient was $335 \mathrm{~min}$ and the blood loss amount was $700 \mathrm{ml}$.

No perioperative complications were found among these seven patients. No blood transfusions were administered to these patients during perioperative and postoperative period. The average hospitalization date was 5.7 days, with an average cost of 61,000 yuan (RMB). There were no fever, wound infestion, secondary haemorrage, ileus and leakage among these seven patients. No patient was lost of follow up in this study. No motor or sensory dysfunction of lower extremity was assessed in these patients. There has no evidence of recurrence during the follow-up period of 24 to 31 months after surgery. 
Table 1 Clinical characteristic of patients

\begin{tabular}{|c|c|c|c|c|c|c|c|c|c|}
\hline Case & Sex & $\begin{array}{l}\text { Age- } \\
\text { ranges }\end{array}$ & $\begin{array}{l}\text { Pre-operative } \\
\text { diagnosis }\end{array}$ & $\begin{array}{l}\text { Tumor size } \\
\left(\mathrm{cm}^{3}\right)^{a}\end{array}$ & $\begin{array}{l}\text { Adjacent } \\
\text { tissues }\end{array}$ & $\begin{array}{l}\text { Operative } \\
\text { time (min) }\end{array}$ & $\begin{array}{l}\text { Blood loss } \\
(\mathrm{ml})\end{array}$ & $\begin{array}{l}\text { Post-operative } \\
\text { diagnosis }\end{array}$ & $\begin{array}{l}\text { Hospitalization } \\
\text { (days) }\end{array}$ \\
\hline 1 & $\mathrm{~F}$ & $45-55$ & Schwannoma & 37.7 & iliac vessel & 60 & 50 & Schwannoma & 3 \\
\hline 2 & $\mathrm{~F}$ & $40-50$ & Schwannoma & 113.0 & iliac vessel & 90 & 100 & Schwannoma & 9 \\
\hline 3 & $\mathrm{~F}$ & $60-70$ & Solitary fibroma & 39.3 & superior rectal artery & 100 & 30 & Solitary fibroma & 5 \\
\hline 4 & $\mathrm{~F}$ & $20-30$ & Schwannoma & 433.4 & intestine & 200 & 600 & Schwannoma & 5 \\
\hline 5 & $\mathrm{~F}$ & $50-60$ & Chordoma & 194.2 & ovarian artery & 335 & 750 & Chordoma & 10 \\
\hline 6 & $\mathrm{~F}$ & $20-30$ & Schwannoma & 141.4 & ureter & 80 & 50 & Schwannoma & 4 \\
\hline 7 & M & $45-55$ & Schwannoma & 96.3 & iliac vessel & 90 & 30 & Schwannoma & 4 \\
\hline
\end{tabular}

Tumor size $=(\pi / 6) \times$ height $\times$ width $\times$ depth

\section{Discussion}

The incidence of sacral tumor is low. It is relatively hard for surgeons to accumulate much experience in the resection of sacral tumors. Therefore, it is of great importance to summarize the surgical outcomes of new technology in the treatment of sacral tumor. The majority of sacral tumors are primary, including chordoma, schwannoma and giant cell tumor. Surgical treatment remains as the optimal choice for primary malignant sacral tumors. As for benign or lowmalignancy sacral tumors when aggravating symptoms or enlargement of tumors occurs during the clinical follow-up, surgery should be taken into consideration However, the complicated anatomical structure, narrow space for operation in the pelvis and abundant presacral vessels make the treatment of sacral tumors extremely challenging [8-10].

In our center, patients with a large mass in the sacrum usually receive hypogastric artery ligation and isolation using the anterior approach, followed by the excision of the tumor through posterior approach. This strategy could provide enough margins for excision and safety related for bleeding from tumor.
However, it would increase the duration of the operation and surgical stress for patients. Several studies have reported the use of a laparoscope to ligate the hypogastric artery and isolate the presacral mass [11-13]. The magnifying function of the laparoscope allows for an en bloc resection without damaging the tumor. But, it is still inconvenient for surgeons to separate related tissue and ligate blood vessels, as laparoscope arms are lack of flexibility in the narrow and deep cavity. The robotic surgical system could provide visual magnification and a high degree of freedom for surgeons. However, no studies have reported the use of the robotic surgical system in the excision of sacral and presacral tumor.

The da Vinci surgical system is widely used in gastrointestinal surgery, urology and gynecological surgery. Therefore, we tried to utilize the robotic surgical system in the treatment of sacral tumor.

According to our experience, the use of the da Vinci surgical system in the treatment of sacral tumors, especially presacral benign tumors, is feasible. We chose the supine position with four trocars to build the robotic surgical system. As these five
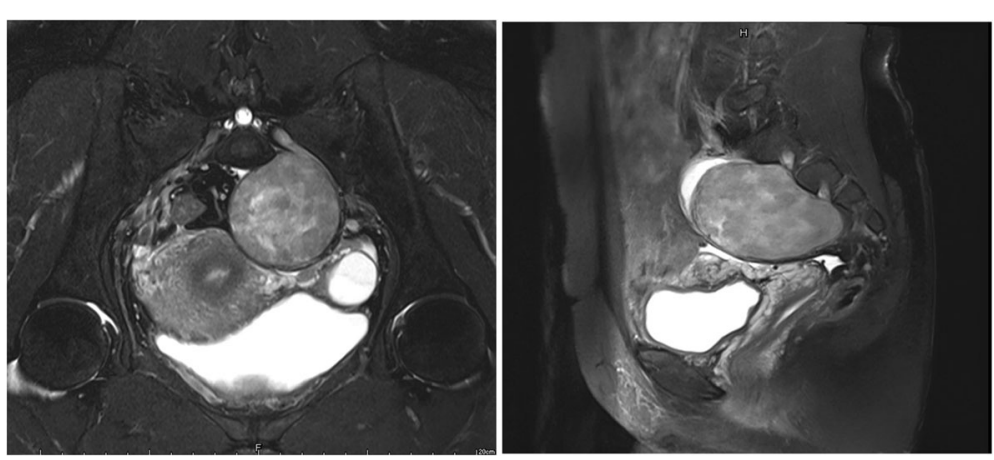

Fig. 2 Patient with small presarcral tumor underwent complete tumor resection by the da Vinci robotic surgical system 


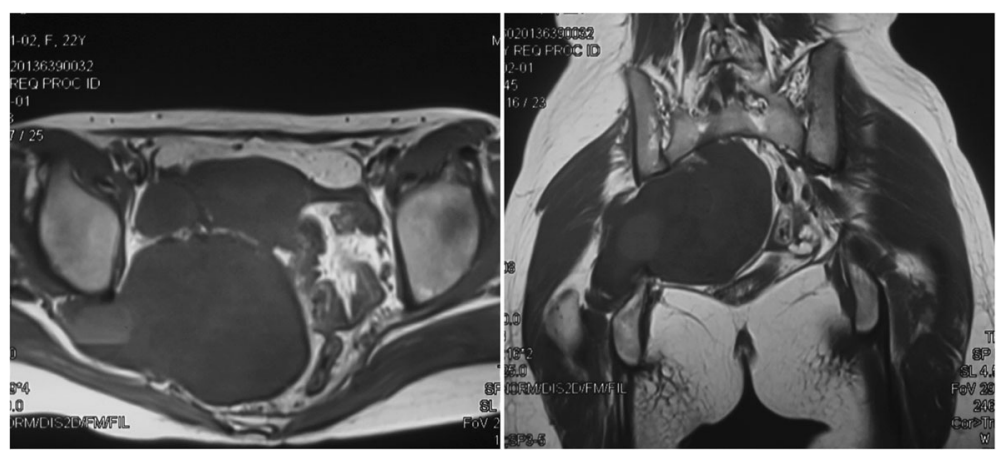

Fig. 3 Patient with large presarcral tumor underwent excision of the presacral tumor by the da Vinci robotic surgical system, followed by a posterior approach

patients were female, the suspension of uterus was taken to expand the field of vision. Three of the five patients underwent total tumor resection using the robotic surgical system. The average operation time was $83.3 \mathrm{~min}$, with blood loss amount of $60 \mathrm{ml}$ for these three patients. This cost less average operative time and less bold loss compared with patients with presacral schwannoma received laparoscopic surgery [14]. The blood loss was much less than that associated with open surgery [15]. Additionally, it could shorten the recovery time for patients. For the other two patients, the robotic surgical system was used to separate organs close to the tumor, which made the resection of the tumor safe through a posterior approach.

Additionally, a multidisciplinary team including surgeons from musculoskeletal oncology, gastrointestinal and urological departments wan strongly recommended to perform robot-assisted surgery for patients with sacral or presacral tumors. However, this study still contained some limitations. The major one was that it was a retrospective study with limitation of enrolled patient number. It restricted the power of our analysis and conclusion. The robot-assisted minimally invasive sacral surgery should be further studies in prospective cohort with more patients included.

\section{Conclusion}

Robot-assisted minimally invasive sacral surgery is a technically feasible and efficent procedure that is associated with minimal blood loss, fewer injuries and short hospitalization. It is particularly suitable for presacral benign tumors.

\section{Funding}

This study was supported by grants from the National Natural Science Foundation of China (81201388 to Jingnan Shen).

\section{Availability of data and materials}

All data generated during this study are included in this published article. The datasets used during the current study available from the corresponding author on reasonable request.

\section{Authors' contributions}

JY and HW contributed to manuscript drafting and interpretation of data. JT contributed to collation and disposal of data, revised manuscript preparation. CZ contributed to patients' follow up. GH and XX contributed to data collation and analysis and patient's treatment. YH and JS contributed to patient's treatment, conception and design of the study and manuscript submission. All authors have read and approved the final manuscript.

\section{Ethics approval and consent to participate}

Written informed consent for participation in the study was obtained from participants. This study was approved by the Institutional Ethical Board of the First Affiliated Hospital of Sun Yat-sen University.

\section{Competing interests}

The authors declare that they have no competing interests.

\section{Publisher's Note}

Springer Nature remains neutral with regard to jurisdictional claims in published maps and institutional affiliations.

Received: 29 November 2017 Accepted: 8 May 2018

Published online: 06 June 2018

\section{References}

1. York JE, Kaczaraj A, Abi-Said D, Fuller GN, Skibber JM, Janjan NA, Gokaslan ZL. Sacral chordoma: 40-year experience at a major cancer center. Neurosurgery. 1999:44(1):74-9. discussion 79-80

2. Kayani B, Hanna SA, Sewell MD, Saifuddin A, Molloy S, Briggs TW. A review of the surgical management of sacral chordoma. Eur J Surg Oncol. 2014; 40(11):1412-20.

3. Varga PP, Szoverfi Z, Lazary A. Surgical treatment of primary malignant tumors of the sacrum. Neurol Res. 2014;36(6):577-87.

4. Corcione F, Esposito C, Cuccurullo D, Settembre A, Miranda N, Amato F, Pirozzi F, Caiazzo P. Advantages and limits of robot-assisted laparoscopic surgery: preliminary experience. Surg Endosc. 2005;19(1):117-9.

5. Rodriguez-Sanjuan JC, Gomez-Ruiz M, Trugeda-Carrera S, Manuel-Palazuelos C, Lopez-Useros A, Gomez-Fleitas M. Laparoscopic and robot-assisted laparoscopic digestive surgery: present and future directions. World J Gastroenterol. 2016:22(6):1975-2004.

6. Baek JH, McKenzie S, Garcia-Aguilar J, Pigazzi A. Oncologic outcomes of robotic-assisted total mesorectal excision for the treatment of rectal cancer. Ann Surg. 2010;251(5):882-6.

7. Wang B, Tu J, Yin J, Zou C, Wang J, Huang G, Xie X, Shen J. Development and validation of a pretreatment prognostic index to predict death and lung metastases in extremity osteosarcoma. Oncotarget. 2015;6(35):38348-59.

8. Doita M, Harada T, Iguchi T, Sumi M, Sha H, Yoshiya S, Kurosaka M. Total sacrectomy and reconstruction for sacral tumors. Spine. 2003; 28(15):E296-301.

9. Hsieh PC, Xu R, Sciubba DM, MJ MG, Nelson C, Witham TF, Wolinksy JP, Gokaslan ZL. Long-term clinical outcomes following en bloc resections for 
sacral chordomas and chondrosarcomas: a series of twenty consecutive patients. Spine. 2009;34(20):2233-9.

10. Zang J, Guo W, Yang R, Tang X, Li D. Is total en bloc sacrectomy using a posterior-only approach feasible and safe for patients with malignant sacral tumors? J Neurosurg Spine. 2015;22(6):563-70.

11. Chen Y, Xu H, Li Y, Li J, Wang D, Yuan J, Liang Z. Laparoscopic resection of presacral teratomas. J Minim Invasive Gynecol. 2008;15(5):649-51.

12. Kohler C, Kuhne-Heid R, Klemm P, Tozzi R, Schneider A. Resection of presacral ganglioneurofibroma by laparoscopy. Surg Endosc. 2003;17(9):1499.

13. Bax NM, van der Zee DC. The laparoscopic approach to sacrococcygeal teratomas. Surg Endosc. 2004;18(1):128-30.

14. Possover M, Kostov P. Laparoscopic management of sacral nerve root schwannoma with intractable vulvococcygodynia: report of three cases and review of literature. J Minim Invasive Gynecol. 2013;20(3):394-7.

15. Song JY, Kim SY, Park EG, Kim CJ, Kim DG, Lee HK, Park IY. Schwannoma in the retroperitoneum. J Obstet Gynaecol Res. 2007;33(3):371-5.

Ready to submit your research? Choose BMC and benefit from:

- fast, convenient online submission

- thorough peer review by experienced researchers in your field

- rapid publication on acceptance

- support for research data, including large and complex data types

- gold Open Access which fosters wider collaboration and increased citations

- maximum visibility for your research: over $100 \mathrm{M}$ website views per year

At BMC, research is always in progress.

Learn more biomedcentral.com/submissions 